\title{
Comparison of multiplex ligation-dependent probe amplification (MLPA) analysis versus multiplex PCR assays in the detection of dystrophin gene
}

\author{
Akram Songol', Bayan Saberipour ${ }^{1}$ and Amirhooshang Bavarsad ${ }^{2 *}$ \\ ${ }^{1}$ Shushtar Faculty of Medical Sciences, Shushtar, Iran \\ ${ }^{2}$ Shushtar Faculty of Medical Sciences, Shushtar, Iran and Department of Internal Medicine, Shushtar \\ Faculty of Medical Sciences, Shushtar, Iran
}

\section{ABSTRACT}

The Duchenne muscular dystrophy (DMD) gene is located in the short arm of the X chromosome (Xp21). It spans 2.4 $\mathrm{Mb}$ of the human genomic DNA and is composed of 79 exons. Mutations in the dystrophin gene results in DMD and Beckers muscular dystrophy. In this study, the efficiency of MLPA over multiplex PCR assays in an Iranian population was investigated.Multiplex PCR assays and multiplex ligation-dependent probe amplification (MLPA) analysis were carried out in 65 patients affected with DMD. Multiplex PCR detected deletions in 51\% of the patients with DMD. MLPA analysis could determine all the deletions detected by the multiplex PCR. Additionally, MLPA was able to identify one more deletion and duplication in patients without detectable mutations by multiplex PCR. Moreover, MLPA precisely determined the exact size of the deletions.Although MLPA analysis is more sensitive for detection of deletions and duplications in the dystrophin gene, multiplex PCR might be used for the initial analysis of the boys affected with DMD in the Iranian population as it was able to detect 95\% of the rearrangements in patients with DMD.

KEY WORDS: DELETION, DUCHENE MUSCULAR DYSTROPHY, DUPLICATION, MLPA, MULTIPLEX PCR

\section{INTRODUCTION}

The Duchenne muscular dystrophy $(D M D)$ gene (Medelian Inheritance in Man MIM 300377) located at Xp21 spans 2.4 $\mathrm{Mb}$ and contains 79 exons. The $D M D$ gene is the largest known human gene, and its product is called dystrophin, which is mainly expressed in the skeletal and cardiac mus-

\section{ARTICLE INFORMATION:}

*Corresponding Author: dramir_hb@yahoo.com Received $5^{\text {th }} \mathrm{Feb}, 2016$

Accepted after revision $28^{\text {th }}$ March, 2016

BBRC Print ISSN: 0974-6455

Online ISSN: 2321-4007

1ini: Thomson Reuters ISI SCI Indexed Journal

NAAS Journal Score : 3.48

- A Society of Science and Nature Publication, 2016. All rights reserved.

Online Contents Available at: http//www.bbrc.in/ cles, with small amounts expressed in the brain. Dystrophin is comprised of an N-terminal actin-binding domain, 24 spectrin-like repeat units interspersed by four hinge regions, a cysteine-rich domain and a C-terminal domain. It is involved in the linkage between the cytoskeletal actin and the extracellular matrix (Blake et al., 2012; Ehmsen et al., 2013, Roberts et al., 2014 and Hoffman et al., 2015). 
Various mutations in DMD gene result in Duchenne muscular dystrophy and Becker muscular dystrophy (DMD/BMD) (Prior \& Bridgeman, 2015). DMD (MIM 310200) is the most common X-linked recessive lethal disease affecting one in 3500 newborn males. Affected boys are characterized by progressive dystrophy of the skeletal muscles and are usually wheelchair-bound before the age of12 years (Emrey, 2002). BMD (MIM 300376) is a milder form of the disease, with an incidence of around one in 12,000 live born males (Bushby, 2012). Patients with BMD have a later age of onset (some as late as 40-50 years of age) and a slower clinical progression. In boys affected by DMD, the prematurely truncated, unstable dystrophins lacking cystein-rich and C-terminal domains are generated. These proteins have completely lost their function as a bridge due to mutations disrupting the open reading frame. In patients with BMD, low levels of full length dystrophin or internally deleted dystrophin resulting from in-frame mutations are detected (Aartsma-Rus, 2006). Deletions or duplications are found in about 60-65\% and 5-10\% of patients with muscular dystrophy, respectively (Den Dunnen et al., 1989 and White et al., 2015).

Although deletions encompass all 79 exons, two deletion hotspots - one including exons 45-55 and the other including exons 2-19 - are recognized. Approximately $30-35 \%$ of the cases with BMD/DMD are caused by point mutations (nonsense or splice sites) or small rearrangements (Muntoni, 2013).Multiplex ligation-dependent probe amplification (MLPA) analysis has proven to be a method of choice for the detection of deletions and duplications (Sellner et al., 2004; Schouten et al., 2012; Schwartz and Dunø, 2015).

Before development of MLPA, detection of deletions and duplications in the DMD gene was mostly carried out by applying Southern blot (Puget, 1999) and multiplex polymerase chain reaction (PCR). Because Southernblotting was a labor-intensive and timeconsuming method, it was replaced by the multiplex PCR (Prior \& Bridgeman, 2015). The most commonly used multiplex PCR protocols cover 18 exons at the deletion hot spots and detect $90-98 \%$ of all deletions (Beggs et al., 1990; Chamberlain et al., 1988). Multiplex PCR is proven to be a method for the rapid detection of deletions in boys affected with DMD; however, it is not efficient for the precise identification of $D M D$ gene duplications in males and heterozygous deletions and duplications in females. The aim of this study was to prove the efficiency of the MLPA analysis in a subset of Iranian patients. Therefore, we used multiplex PCR assays followed by MLPA analysis in 65 cases with DMD.

\section{MATERIAL AND METHODS}

\section{PATIENT SAMPLES}

This study was performed in a total of 65 boys affected with DMD from the central provinces of Iran referred by the neurology specialists to Genetic Lab, AlhadiHospital, for genetic analysis of their DMD gene. The diagnosis of DMD was according to the clinical features, electromyography, an elevated serum creatinekinase activity and an X-linked family history. After obtaining informed consent, genomic DNA was extracted from blood leukocytes using a QIAampDNA mini kit (Qiagen, Hilden, Germany). The exact DNA concentration was determined using a NanoDrop instrument (Thermo 2000c) after dilution to $50 \mathrm{ng} / \mathrm{ml}$.

\section{MULTIPLEX PCR}

Two multiplex PCR assays covering exons 1, 3, 4, 6, 8, $12,13,17,19,43,44,45,46,47,48,50,51,52$, and 51 in the hot spot regions of the $D M D$ gene were performed in a total volume $50 \mu \mathrm{l}$ according to the technique described by Chamberleidon and Beggs. [16,17] Multiplex PCR products were visualized on $2 \%$ agarose gel.

\section{MLPA ANALYSIS}

MLPA analysis was carried out using the SALSA probe mix 034 (DMD exons 1-10, 21-30, 41-50, and 61-70) and 035 (DMD exons 11-20, 31-40, 51-60, and 71-79) according to the manufacturer's instructions. In brief, the ligation reaction was performed using $200 \mathrm{ng}$ of target DNA in the following steps: Denaturation at $98^{\circ} \mathrm{C}$ for $5 \mathrm{~min}$, hybridization with the SALSA probe mix 034 and 035 at $60^{\circ} \mathrm{C}$ for $16 \mathrm{~h}$ and ligation by Ligase- $65 \mathrm{mix}$ at $54^{\circ} \mathrm{C}$ for $15 \mathrm{~min}$, and then ligase inactivation by incubation at $98^{\circ} \mathrm{C}$ for 5 min. Finally, multiplex PCR was performed using the specific SALSA FAM PCR primers, dNTPs, PCR buffer and polymerase for 30 cycles $\left(95^{\circ} \mathrm{C}\right.$ for $30 \mathrm{~s}, 60^{\circ} \mathrm{C}$ for $30 \mathrm{~s}$ and $72^{\circ} \mathrm{C}$ for $\left.1 \mathrm{~min}\right)$. The fragments were analyzed on a 3100 capillary sequencer (Applied Biosystems, UK) with a $36-\mathrm{cm}$ capillary array and POP-4TM polymer (Applied Biosystems, UK) by mixing with $0.2 \mu \mathrm{l}$ of the GeneScanTM-500 ROXTM size standard (Applied Biosystems, UK) and $10 \mu \mathrm{l}$ of HiDiFormamide (Applied Biosystems, UK). The results (size and peak area) were analyzed using GeneMarkersoftware.

\section{RESULTS AND DISCUSSION}

Multiplex PCR assays indicated that 38 of 65 boys affected with DMD have exon deletions. However, MLPA 
analysis indicated one more deletion and duplication. These new mutations identified by MLPA were confirmed by direct sequencing of the relevant exons using primers described earlier (Sedlácková et al., 2015). Furthermore, two deletions with different sizes were identified than what was detected by multiplex PCR. In male patients, total absence of MLPA peak areas indicated deletions of one or more exons, and multiplication of MLPA amplification products indicated duplications. Among the 40 identified rearrangements, 36 were located in the central hot spot region, including exons 44-55. Four deletions were identified in the 5 hot spot region.

In this study, we performed multiplex PCR assays and MLPA analysis to identify deletions and duplications in the $D M D$ gene. We used multiplex PCR as the first step for identification of deletions in male patients. Then, MLPA analysis was performed to confirm the results obtained by the multiplex PCR.Because the $D M D$ gene is $\mathrm{X}$-linked, deletions are easily identified by conventional multiplex PCR in male patients. However, this method cannot be used for carrier analysis in women and detection of duplications and uncommon deletions in men with DMD. In addition, multiplex PCR is more difficult to be performed because there are different primer pairs for exons in the hot spot regions, and it is not possible to amplify these exons in a single reaction. However, MLPA can be used to detect rearrangements in all exons of dystrophin gene in both females and males by only two reaction sets (Yau et al., 1996; Abbs and Bobrow, 1992).

In our study, two multiplex assays covered 19 exons of the $D M D$ gene, and in 51\% of the cases deletions were identified. However, because all 79 exons of the $D M D$ gene are included in two separate MLPA kits, MLPA analysis of subjects revealed the exact range of deletion in two patients and two more rearrangements. In two patients, multiplex PCR assays detected deletion of exon 50; however, deletion of exons 49-50 was detected by MLPA analysis. In addition, duplication of exon 51 and deletion of exon 53 were detected by MLPA analysis. Single duplication of exon 51 is not identified in other populations. However; duplication of exons 51-55 was reported in a Taiwanese patient (Hwa et al., 2015).

Exon 51 duplication was identified in an 11-yearold boy whose mother did not show any mutation with MLPA analysis. The identified duplication in the boy might be a de novo mutation, or it could have resulted from maternal germ line mosaicism. These findings indicated that MLPA analysis is more sensitive and reliable than conventional multiplex PCR for the detection of exon deletions and duplications. Although deletions and duplications can occur in any exon of the DMD gene, their frequency is higher in two regions - one located in the 5 region (called minor hot spot) and the other located in the central part (called major hot spot). In the present study, 90\% of the rearrangements were located in the central hot spot region between exons 44 and 55. Eight of the 36 deletions located in central hotspot region were deletion of exons 45-51. In another study performed by Khordadpoor- Deilamani et al. (2015) 52 of 53 deletions in the dystrophin gene were detected by multiplex PCR. This indicates that 98.11\% deletions in dystrophin gene are located in hot spot regions, which is in agreement with our findings.

In the remaining cases without detectable deletion or duplication, after confirmation of the diagnosis by the neurology specialists, DNA sequencing can be used for identification of point mutations, small insertion or deletion that are scatteredthroughout the dystrophin gene. Alternatively, a dense set of polymorphic and dymorphic markers can be used to track mutation in patients with a family history. Identification of deletions and duplications in the DMD gene is important for prenatal diagnosis and determination of genotype-phenotype correlation. In recent years, MLPA is recommended to be used as the method of choice for detection of deletions and duplications in the DMD gene. In this study, we detected 95\% of the deletions by multiplex PCR, which shows that most of the deletions in our population are located in the hot spot regions. These findings indicate that an initial analysis of patients with DMD using multiplex PCR and then MLPA analysis of patients without detectable mutation is more practical in our population. This approach is described to be a precise and cost-effective tool for DMD diagnosis in developing countries as described by Murugan et al. (2015) in the Indian population.

\section{ACKNOWLEDGMENTS}

This study was funded by grant number 189087 from deputy for research, Shushtar University of Medical Sciences, Khozestan, Iran. The authors are grateful to patients with DMD for their participation in this study.

\section{REFERENCES}

Aartsma-Rus A, Van Deutekom JC, Fokkema IF, Van Ommen GJ, Den Dunnen JT (2006). Entries in the Leiden Duchennemuscular dystrophy mutation database: An overview of mutation types and paradoxical cases that confirm the readingframerule. Muscle Nerve;34:135-44.

Abbs S, Bobrow M. (1992). Analysis of quantitative PCR for the diagnosis of deletion and duplication carriers in the dystrophingene. J Med Genet;29:191-6.

Abbs S, Yau SC, Clark S, Mathew CG, Bobrow M. (1991). A convenient multiplex PCR system for the detection of dystrophingene deletions: A comparative analysis with cDNAhybridisation shows mistypings by both methods. J Med Genet;28:304-11. 
Beggs AH, Koenig M, Boyce FM, Kunkel LM. (1990). Detection of $98 \%$ of DMD/BMD gene deletions by polymerase chain reaction. Hum Genet;86:45-8.

Blake DJ, Weir A, Newey SE, Davies KE. (2012). Function and genetics of dystrophin and dystrophin-related proteins in muscle. Physiol Rev;82:291-329.

Bushby KM, Thambyayah M, Gardner-Medwin D. (2012). Prevalence and incidence of Becker muscular dystrophy. Lancet;337:1022-4.

Chamberlain JS, Gibbs RA, Ranier JE, Nguyen PN, Caskey CT. (1988). Deletion screening of the Duchenne muscular dystrophy locus via multiplex DNA amplification. Nucleic Acids Res;16:11141-56.

Den Dunnen JT, Grootscholten PM, Bakker E, Blonden LA, Ginjaar HB, Wapenaar MC, (1989). Topography of the Duchenne muscular dystrophy (DMD) gene: FIGE and cDNA analysis of 194 cases reveals 115 deletions and 13 duplications. Am J Hum Genet;45:835-47.

Ehmsen J, Poon E, Davies K. (2013). The dystrophin-associated protein complex. J Cell Sci;115:2801-3.

Emery AE. (2002). The muscular dystrophies. Lancet;359:687-95.

Hoffman EP, Brown RH Jr, Kunkel LM. (2015). Dystrophin: The protein product of the Duchenne muscular dystrophy locus. Cell;51:919-28.

Hwa HL, Chang YY, Chen CH, Kao YS, Jong YJ, Chao MC, (2015). Multiplex ligation-dependent probe amplification identification of deletions and duplications of the Duchenne muscular dystrophy gene in Taiwanese subjects. J Formos Med Assoc;106:339-46.

Khordadpoor-Deilamani F, Akbari MT, Nafissi S, Zamani G. (2015). Dystrophin gene mutation analysis in Iranian males and females using multiplex polymerase chain reaction and multiplex ligation-dependent probe amplification methods. Genet Test Mol Biomarkers;15:893-9.

Muntoni F, Torelli S, Ferlini A. (2013). Dystrophin and mutations: One gene, several proteins, multiple phenotypes. Lancet Neurol;2:731-40.
Murugan S, Chandramohan A, Lakshmi BR. (2015) .Use of multiplex ligation-dependent probe amplification (MLPA) for Duchenne muscular dystrophy (DMD) gene mutation analysis. Indian J Med Res;132:303-11.

Prior TW, Bridgeman SJ. (2015). Experience and strategy for the molecular testing of Duchennemuscular dystrophy. J MolDiagn; 7:317-26.

Puget N, Stoppa-Lyonnet D, Sinilnikova OM, Pagès S, Lynch HT, Lenoir GM, (1999). Screening for germ-line rearrangements and regulatory mutations in BRCA1 led to the identification of four new deletions. Cancer Res;59: 455-61.

Roberts RG, Coffey AJ, Bobrow M, Bentley D.R. (2014) Determination of the exon structure of the distal portion of the dystrophingene by vectorette PCR. Genomics 13:94250 .

Schouten JP, McElgunn CJ, Waaijer R, Zwijnenburg D, Diepvens F, Pals G. (2012). Relative quantification of 40 nucleic acid sequences by multiplex ligation-dependent probe amplification. Nucleic Acids Res;30:e57.

Schwartz M, Dunø M. (2015). Multiplex ligation-dependent probe amplification is superior for detecting deletions/duplications in Duchenne muscular dystrophy. Clin Genet;67: 189-91.

Sedlácková J, Vondrácek P, Hermanová M, Zámecník J, Hrubá Z, Haberlová J, (2012). Point mutations in Czech DMD/BMD patients and their phenotypic outcome. NeuromusculDisord;19:659-53.

Sellner LN, Taylor GR. (2004). MLPA and MAPH: New techniques for detection of gene deletions. Hum Mutat;23: 413-9.

White SJ, Aartsma-Rus A, Flanigan KM, Weiss RB, Kneppers AL, Lalic T, (2015). Duplications in the DMD gene. Hum Mutat;27:938-45.

Yau SC, Bobrow M, Mathew CG, Abbs SJ. (1996). Accurate diagnosis of carriers of deletions and duplications in Duchenne/Becker muscular dystrophy by fluorescent dosage analysis. J Med Genet;33:550-8. 